\title{
Establishing a mental health liaison attachment with primary care
}

\author{
Tom Burns \& Rob Bale
}

The role of the general practitioner (GP) in the care of individuals with mental health problems has long been recognised. Goldberg \& Huxleys' (1980) pioneering work on the pathways to mental health care demonstrated that only a fraction of identified mental health problems are referred on to psychiatrists. Goldberg \& Bridges (1987) estimated that between 20 and $25 \%$ of a GP's workload concerns mental health, with only about $5 \%$ referred on to psychiatrists. Shepherd (1991) insisted that the only real hope for significant improvement in mental health care lay in the improvement of GP provision - there will simply never be enough psychiatrists.

The past 15 years have seen real evidence of this improvement, with a growing literature on mental health problems in primary care (Kendrick et al, 1996). This charts a 'technology export' of psychiatrists and psychologists training GPs in assessment techniques (Gask et al, 1987, 1988) and, more recently, specific therapeutic techniques such as cognitive-behavioural therapy for depression (Scott et al, 1993). Burns et al (1995) have examined transfer of learning in the opposite direction.

Most GP mental health work concerns minor psychiatric morbidity, but not all. Despite changes in mental health practice, GPs have remained central figures in the care of the severely and longterm mentally ill. Studies of patients suffering from schizophrenia (Melzer et al, 1991) confirm the GP as the health professional most likely to be in contact a year after hospital discharge. GPs show an overall willingness to be involved in the care of this patient group, but only if in collaboration with, and supported by, the mental health team (Kendrick et al, 1991).
At its very least, such support requires prompt and effective communication between primary and secondary care. Although over $80 \%$ of England and Wales is served by sectorised community mental health teams (CMHTs) (Johnson \& Thornicroft, 1993), GPs continue to complain of difficulties in communication. Some of these are practical consequences of a dispersed and multi-disciplinary service; questions of who to contact and where. Other problems reflect the inherent difficulties of letter-writing between professionals with different training and expectations (Pullen \& Yellowlees, 1985). Psychiatrists and GPs have explored a number of strategies to improve this situation.

Innovative possibilities range from shared care records (Essex et al, 1990) to mental health services based totally within primary care (Wilkinson et al, 1995), which require levels of commitment prohibiting large-scale adoption. Establishing a liaison link, however, is an obvious and fairly simple approach to improving communication and coordination, which its proponents insist saves as much time as it takes.

\section{Psychiatric liaison with general practice}

Horder's practice had been regularly visited by a consultant psychiatrist as early as 1965 (Horder, 1988). Professional awareness of this approach became widespread in 1984 with the publication of articles by Strathdee \& Williams and by Tyrer (Strathdee \& Williams, 1984; Tyrer, 1984). Since

\footnotetext{
Tom Burns (corresponding author) is Professor of Community Psychiatry and Rob Bale is Lecturer in Community Psychiatry at St George's Hospital Medical School, Jenner Wing, Cranmer Terrace, Tooting, London SW17 0RE. They are currently participating in a large, multi-centre trial of intensive case management. Professor Burns has established an assertive community treatment service in Wandsworth.
} 
these two articles there has been a steady flow of publications on psychiatry/primary care liaison. Most describe different types of approach and their perceived benefits (Tyrer, 1985; Strathdee, 1987; Low \& Pullen, 1988; Tyrer et al, 1990). Attempts have been made to compare the results of different approaches (Creed \& Marks, 1989) on the use of secondary services (Tyrer et al, 1984; Creed \& Marks, 1989) but patient acceptability and pattern of service use have also been explored (Tyrer, 1984; Tyrer et al, 1984).

As yet, there is no accepted classification of different types of liaison. What they all have in common is an undertaking to meet face-to-face on a regular basis. Virtually everything else is negotiable - who attends, for how long, how frequently, the content of the discussion (clinical, academic, organisational) and the style of discourse. More will probably depend on the personalities, relationships and confidence of those involved than on local clinical needs. A definitive classification would be premature. An earlier classification comprised 'replacement', 'increased throughput' and 'liaison attachment' models (Williams \& Clare, 1981). More recently, three broad categories have been outlined by Strathdee \& Williams (1984): consultation; shifted outpatients; and liaison attachment.

\section{Consultation}

This is the earliest of the three approaches and derives from the Balint tradition (Balint, 1964) of meetings with a psychotherapist or psychiatrist to discuss, in depth, one complex patient. This was an opportunity to deepen understanding of the doctor-patient relationship and explore both transference and counter-transference issues, as much as to improve individual patient management. It is less prominent in recent literature.

\section{Shifted out-patients}

This consists of the psychiatrist conducting a regular clinic in the primary care setting. In Strathdee \& Williams' (1984) survey it was the most common form of liaison attachment. Psychiatrists considered the advantages to include easier and earlier referral, decrease in admissions, continuity of care, easier access to background information and possibility of joint assessments. The drawbacks were administrative.

Satisfaction with the shifted out-patients model has waned. Most advantages derive from the associated consultation and discussion between professionals, rather than from assessments taking place away from the hospital. The level of contact between GP and psychiatrist can rapidly fall off (especially if the consultant delegates the clinic to junior medical staff). This is no longer the dominant model of GP/psychiatry liaison.

There is, however, a current increase in shifted out-patient clinics in other hospital specialities because of fund-holding. Their origins lie more in fund-holding GPs wanting greater control over the specialist services offered to their patients, rather than a desire for closer working relationships or liaison. This shift in the balance of power between primary and secondary care may have profound implications for the shape of psychiatric liaison in the future.

\section{Liaison attachment}

This term is used to describe regular meetings between primary and secondary care teams where patients who may or may not have been assessed by the secondary care team are discussed. In Creed \& Marks' (1989) paper 85\% of patients discussed had no contact with secondary services. More recently, however (as increasingly more disabled patients are supported in the community), the emphasis may be on patients with ongoing involvement by both teams. Their central purpose is to ensure that both sides are fully informed of what is going on (Midgeley et al, 1996). Information and expertise goes both ways and, despite the focus on current problems, discussion can, and does, extend to feedback about discharged patients or in-patients. Academic and administrative issues can be touched on. This approach is compatible with more formal consultations (Creed \& Marks, 1989) or a whole range of complementary contacts such as shifted out-patients or linked and on-site mental health staff (Tyrer et al, 1990).

A survey of psychiatrists' opinions of the value of liaison attachments highlighted easier and earlier referral processes, availability of background information, continuity of care, prevention of admissions and the possibility of joint assessments and treatment (Strathdee, 1987). The same author surveyed GPs who considered the main advantages to be regular discussion and feedback, improved professional education, altered referral spectrum, decreased admissions, ease of referral, joint treatment and continuity of care.

\section{Problems with liaison attachments}

Liaison attachments continue to be encouraged (Jenkins, 1992) but are not without their critics. The 
tendency for liaison links to be part of a larger shift in service (Tyrer et al, 1989) has made them difficult to evaluate. Any hope for reduction in referrals has certainly not materialised. Most authors find an increase (Low \& Pullen, 1988; Tyrer et al, 1990) and this has been our experience in south London. Initial increases, however, accompany most initiatives which improve access. Tyrer and colleagues do report a reduction in admissions in their 1984 and 1990 papers but it is difficult to know how much is attributable to the liaison attachment and how much to concurrent changes in service provision and staff attitudes.

There is concern that liaison attachments will shift attention away from the severely mentally ill towards patients with more neurotic disorders. The Edinburgh study (Low \& Pullen, 1988) supported this idea, but Tyrer (1984) found the same spectrum of disorders in hospital outpatients and in primary care clinics. Creed \& Marks (1989) reported the content of their liaison meetings to focus on minor morbidity but Midgley et al (1996) found their meetings focused more on longterm patients and those with psychotic disorders.

\section{Establishing a liaison attachment}

There is no pressure to establish a traditional consultation service and only weak support for the value of a shifted out-patient approach. Only forms of the liaison attachment approach will be considered further.

Given the enormous variation in the practice of both CMHTs and GPs there can be no 'off the peg' liaison attachment. A series of questions need to be asked to guide practice. Do not be surprised if the model which fits one group practice does not suit another. Clarity of purpose is essential but flexibility is a cardinal virtue.

\section{Who wants the attachment?}

A liaison attachment will flourish most vigorously if it is sought by both mental health services and general practitioners. Usually this will happen when there is already a degree of personal contact established. Discussions of mutual patients demonstrates to both partners the different information they have and the various constraints under which they work. It becomes clear that a more rounded understanding of difficult patients will lead to fewer headaches for all involved. The recognition that they may sometimes have been quite innocently undermining each others' efforts can be a real spur to better cooperation.

More care is needed if the motivation is onesided. GPs may request it because they find existing communication (letters and discharge summaries) unhelpful, especially if they are ambiguous about who should do what. Also many GPs consider that psychiatrists underestimate the difficulties they have with patients such as those with personality disorders or alcohol abuse, whom they (GPs) cannot refuse to see. Psychiatrists may want to establish a liaison because they find referrals poorly formulated or inappropriate or feel that patients are given misleading expectations. Lastly the motivation may come from neither GP nor psychiatrist but from local agreements about services. Our mental health unit (Pathfinder) requires CMHTs to offer a liaison service to GPs as part of its minimum contract specification with the Health Authority.

The motivation and expertise of all involved will have a substantial impact on the structure and content of any liaison. Mistakenly assuming that the same approach must be applied to all GPs leads many psychiatrists to decide that liaison attachments are impractical and an inefficient use of time.

Not only is there no need to apply the same approach to all practices, but also there is no need to start contact with all practices at the same time. It is best to start where one feels most comfortable. Large practices with a high rate of referral are often well known and may have an interest in mental health. If choosing between the practice that is the highest referrer and the one you have best relationships with, choose the latter. Become familiar with the process and acquire confidence before taking on trickier situations. There are a series of diplomatic challenges ahead which need to be slowly resolved practice by practice and it is best to start with the easiest.

\section{Where and how frequent?}

Almost invariably meetings will take place in the primary care surgery. This accommodates for some partners having to come a bit late or leave a bit early. Most practices have regular lunchtime meetings, and it is best to try and integrate liaison with one of these. Sometimes single-handed GPs will prefer the meeting to be in the team base or hospital, perhaps because they do not have an adequate meeting room or because they value the visit. This is more vulnerable to cancellation and attrition. Surgery meetings allow members of the primary care team who might not wish to attend 
regularly to pop in to discuss specific patients. It also provides a more detailed and accurate 'feel' of the practice and their management of mental health problems.

Monthly meetings seem the best option. A monthly lunchtime meeting for one hour is adequate for even the largest practice and is easily remembered. It has the advantage that the meeting may not necessarily take a full hour (psychiatrists have a reputation among GPs for spinning meetings out too much). Finishing 15 or 20 minutes early on occasions emphasises the task-oriented nature of the activity and generally pleases everybody. It also gives the opportunity for individual discussions of specific issues without anybody being late. In rural areas, where the GPs may take considerably more responsibility for management, there have been successful liaison meetings fortnightly, but this is exceptional. Recent pressure of administration and competition with other specialities has forced trials with six-weekly meetings. These are noticeably less successful double bookings occur frequently and they do not become established in the collective consciousness. Shorter monthly meetings are preferable.

\section{Who should attend?}

This is a tricky question. While a single team member is sometimes all that is possible (or all that is wanted) it cannot achieve the level of mutual understanding that comes from meeting with the full team. If none of the doctors attend, the GPs can feel short-changed (they often want to discuss difficult situations doctor-to-doctor) and the meeting loses status. On the other hand, if only the doctors go, it can devalue the team and lead to a narrow focus. Having to say, "I'm not sure about that patient. I'll have to ask Jean the occupational therapist" undermines the meeting's immediacy.

Optimally, the whole team should diary the meetings, ensuring about two-thirds will attend. Nothing is more damaging to the survival of liaison than all the GPs turning up to meet only one or two team members. Similarly, swamping a twoperson practice with a team of 12 does not make for easy dialogue. About equal numbers from each side seems to feel best. Beware assuming that attending en masse with the whole team will be seen as evidence of your democratic approach to work - some GPs may see it as the hospital consultant bringing his or her entourage.

Starting as one means to go on or slowly building up depends on judgement of the relationships established. Certainly, where these are only beginning, or if the GPs indicate anxiety or uncertainty, it may be best to start with the one or two team members the GPs know best.

\section{Structure and content of meetings}

For a liaison attachment to flourish it must serve a recognised need for both parties and its form must reflect its function. GPs are comfortable with a rapidly shifting agenda - they move swiftly from one patient to another and from clinical to administrative issues and back again. The main focus needs to be on patient management in a dialogue between equals. Joint problem-solving with difficult patients (e.g. "We're at our wits end with Mrs A. We simply can't get her to stay away from her ex-husband and it's undermining both of them. Have you any ideas?") will foster good working relationships. For example, an informal joint audit of a suicide (Kendrick et al, 1994) fulfilled a function of mutual reassurance but acknowledged realistic limitations regarding what can be achieved. Such openness reduces defensiveness and facilitates effective liaison.

Liaison meetings are dialogues, not presentations. Their strength lies in the to and fro of the discussion. While there is an advantage in having a fairly clear shared view of their overall structure, any formal agenda is likely to stifle creativity. A study of the content of liaison meetings in two Wimbledon practices emphasised this brevity, with most patients taking up only two to three minutes of discussion and a high rate of information exchange (Midgeley et al, 1996).

Some sort of list is, however, useful. Most computer databases will allow for the extraction of team patients by keyworker or by GP practice. Taking along a list of the patients under current care can be very useful, although it is important not to mention every one as this easily turns the meeting into an empty ritual. Some sort of rough prioritisation helps, perhaps always mentioning the patients assessed and discharged by the team since the last meeting. Allowing the most difficult patients to dominate the meeting makes obvious sense.

Non-clinical matters are often important parts of these meetings. Changes in services may be talked about, and policy decisions debated and clarified. A moderate amount of 'whinging' about the state of the NHS and the current reforms helps underline that we're all on the same side, even when some patient problems can make it seem otherwise. It is a good sign when both sides can ask for more general advice (e.g. "Tell us about these SSRIs. Is there any real difference between them or is that just sales pitch?" or alternatively 
"This is a type of antihypertensive I haven't come across before. What's it like? Could it be the cause of his tiredness?"). This is not restricted to doctors - psychologists may be asked to explain the principles of cognitive-behavioural therapy or the features of post-traumatic stress disorder by a GP who would not otherwise consider attending a course to learn about them.

Quite often tricky issues will be raised with an individual team member as the meeting breaks up. It is important not to respond as a group therapist. If the GP considers the issue not to involve the whole team, he may have a very good reason for it or he may simply be anxious about exposing his uncertainty. These exchanges can be very productive and may or may not benefit from feeding back into the meetings later. For example, advice can be sought about a prominent local figure who will not contemplate referral, a complaint about a team member that needs exploring may have been made to the GP, or preliminary discussions about some political or administrative matter need to be flagged up.

\section{Sorting out difficulties}

GPs, like psychiatrists, feel they are subject to unreasonable and often mutually incompatible pressures. Like us they have been obliged to adapt rapidly to changing conditions of practice accompanied by mountains of bureaucracy. Add to this the inherent contradiction of 'a primary care-led NHS' (emphasising individual choice) and the government policy of targeting mental health service resources on the severely mentally ill (requiring coordination and some uniformity of provision), and it is not surprising that there should be some friction points. It is important to be aware of the difficulties most likely to arise.

GPs cannot refuse to see patients (unless they remove them from their list), whereas psychiatrists can say they have nothing further to offer. It is important to maintain this service difference while being sensitive about it and being prepared to be flexible. Liaison meetings give an opportunity to explain why one cannot do more and to show how one has tried. It helps to acknowledge the difficulties GPs face with unmeetable demands. Support and encouragement with drawing boundaries may make the decision more palatable. Accepting patients back temporarily for respite (respite for GP or family) can avoid resentment and help clarify the nature of the primary/ secondary care divide. A clearer recognition of the pressure GPs are under to provide temporary relief when cure is not possible (e.g. the detoxification of alcoholics, brief in-patient spells for dependent importunate relatives) can be an important learning experience for CMHTs.

Attention to detail is important. Unpunctuality and blocking-in parking spaces can be disastrous. The level of inter-professional rivalry which is common in mental health services is best not exported. The social structure of general practice is profoundly different to that of hospital teams. An understanding of the very real hierarchy of general practice, despite its informal style (Burns et al, 1994), is essential if errors are to be avoided.

When clinical mistakes occur they should be acknowledged promptly. Liaison meetings offer unrivalled opportunities to make explicit the processes involved in coming to decisions and recognising the absence of certainty. GPs are used to working with incomplete information and having no easy answers. They are unlikely to be over-critical if they are acknowledged as professional equals in the task.

\section{Conclusions}

There is much overlap between the work of GPs and psychiatrists. They share a commitment to long-term disorders and both professions emphasise a holistic approach to patient care, with due consideration being given to social and family factors. The clinical interview is the basic tool of the trade for both of us, and although its form is somewhat different, the establishment of a trusting long-term relationship is essential to both our practices. As psychiatry and mental health practice become less dependent on institutional care, the need for close working relationships is increasingly obvious. Regular, face-to-face meetings between mental health teams and GPs have proved to be a time-efficient investment both for improving patient care and for avoiding potential mishaps.

\section{References}

Balint, M (1964) The Doctor, His Patient and the Illness (2nd edn). London: Pitman Medical.

Burns, T., Silver, T., Freeling, P., et al (1994) GP experience for psychiatrists. A study of feasibility and acceptability. Psychiatric Bulletin, 18, 286-288.

-, MacDonald, L., Sibbald, B., et al (1995) Educational assessment of general practice experience for psychiatric trainees. Medical Education, 29, 159-165.

Creed, F. \& Marks, B. (1989) Liaison psychiatry in general practice: a comparison of the liaison-attachment scheme and shifted outpatient clinic models. Journal of the Royal College of General Practitioners, 39, 514-517. 
Essex, B., Doig, R. \& Renshaw, J. (1990) Pilot study of records of shared care for people with mental illnesses. British Medical Journal, 300, 1442-1446.

Gask, L., McGrath, G., Goldberg, D., et al (1987) Improving the psychiatric skills of established general practitioners: evaluation of group teaching. Medical Education, 21, 362-368.

—, Goldberg, D., Lesser, A. L., et al (1988) Improving the psychiatric skills of the general practice trainee: as evaluation of a group training course. Medical Education, 22, 132-138.

*Goldberg, D. P. \& Huxley, P. (1980) Mental Illness in the Community. London: Tavistock.

- \& Bridges, K. (1987) Screening for psychiatric illness in general practice: the general practitioner versus the screening questionnaire. Journal of the Royal College of General Practitioners, 37, 15-18.

Horder, J. (1988) Working with general practitioners. British Journal of Psychiatry, 153, 513-520.

Jenkins, R. (1992) Developments in the primary care of mental illness - a forward look. International Review of Psychiatry, 4, 237-242.

Johnson, S. \& Thornicroft, G. (1993) The sectorisation of psychiatric services in England and Wales. Social Psychiatry and Psychiatric Epidemiology, 28, 45-47.

*Kendrick, T., Sibbald, B., Burns, T., et al (1991) Role of general practitioners in care of long term mentally ill patients. British Medical Journal, 302, 508-510.

- Tylee, A. \& Burns, T. (1994) Teamwork in the community. In Psychiatry and General Practice Today (eds I. Pullen, G. Wilkinson, A. Wright, et al), pp. 265-279. London: Royal College of Psychiatrists.

-, - \& Freeling, P. (eds) (1996) The Prevention of Mental Illness in Primary Care. Cambridge: Cambridge University Press.

Low, B. \& Pullen, I. (1988) Psychiatric clinics in different settings. A case register study. British Journal of Psychiatry, 153, 243-245.

*Melzer, D., Hale, A., Malik, S., et al (1991) Community care for patients with schizophrenia one year after hospital discharge. British Medical Journal, 303, 1023-1026.

Midgeley, S., Burns, T. \& Garland, C. (1996) What do mental health teams and general practitioners talk about? Descriptive analysis of liaison meetings. British Journal of General Practice, 46, 69-71.

Pullen, I. \& Yellowlees, A. (1985) Is communication improving between general practitioners and psychiatrists? British Medical Journal, 290, 31-33.

Scott, C., Scott, J., Tacchi, M. J., et al (1993) Abbreviated cognitive therapy for depression: a pilot study in primary care. Behavioural and Cognitive Psychotherapy, 22, 57-64.

Shepherd, M. (1991) Primary care psychiatry: the case for action. British Journal of General Practice, 41, 252-255.

*Strathdee, G. (1987) Primary care-psychiatry interaction: a British perspective. General Hospital Psychiatry, 9, 102-110.

* — \& Williams, P. (1984) A survey of psychiatrists in primary care: the silent growth of a new service. Journal of the Royal College of General Practitioners, 34, 615-618.

*Tyrer, P. (1984) Psychiatric clinics in general practice. An extension of community care. British Journal of Psychiatry, 145, 9-14.

- (1985) The Hive System. A model for a psychiatric service. British Journal of Psychiatry, 146, 571-575.

- Seivewright, N. \& Wollerton, S. (1984) General practice psychiatric clinics. Impact on psychiatric services. British Journal of Psychiatry, 145, 15-19.

- Turner, R. \& Johnson, A. (1989) Integrated hospital and community psychiatric services and use of inpatient beds. British Medical Journal, 299, 298-300.

* - Ferguson, B. \& Wadsworth, J. (1990) Liaison psychiatry in general practice: the comprehensive collaborative model. Acta Psychiatrica Scandinavica, 81, 359-363.

Wilkinson, G., Piccinelli, M., Falloon, I., et al (1995) An evaluation of community-based psychiatric care for people with treated long-term mental illness. British Journal of Psychiatry, 167, 2637.

Williams, P. \& Clare, A. (1981) Changing patterns of psychiatric care. British Medical Journal, 282, 375-377.

* indicates articles of particular interest 